\title{
Trends in reported cases of donovanosis in Durban, South Africa
}

\author{
Nigel O’Farrell
}

\begin{abstract}
Objective-To investigate recent trends in reported cases of donovanosis (granuloma inguinale) in Durban, South Africa.

Design-The annual reports of the Medical Officer of Health for Durban 1958-1988 were reviewed to identify cases of donovanosis, genital ulcer disease (GUD) and new patients with sexually transmitted diseases (STD). A rapid staining technique for the detection of Donovan bodies was introduced in 1988.

Setting-City Health STD Clinic, King Edward VIII Hospital, Durban.

Results-An initial peak was identified in men $1969-1974$. A second peak was recorded in 1988 when reported cases of donovanosis (313) were the highest since records commenced. Both peaks were unrelated to either increases in the numbers of new attenders with STD or patients with GUD.

Conclusion-The recent increase in donovanosis in Durban may reflect either a new epidemic or under-reporting of a disease previously diagnosed on clinical grounds. Improved control of donovanosis, a condition sometimes causing extensive GUD, and which has been implicated in HIV-1 transmission in local men, should be targeted in HIV control programmes.
\end{abstract}

(Genitourin Med 1992;68:366-369)

\section{Introduction}

Donovanosis is a cause of genital ulcer disease (GUD) found mainly amongst populations with poor socio-economic conditions and low standards of genital hygiene. Major epidemics have been recorded in Dutch South New Guinea ${ }^{1}$ and Papua New Guinea ${ }^{2}$ but since the widespread use of antibiotics the numbers of cases reported worldwide has decreased markedly. ${ }^{3}$ In Africa, until now it has been regarded as a relatively minor problem ${ }^{3-5}$. No epidemics have been recorded but significant numbers of cases have been diagnosed in Zambia, ${ }^{6} \mathrm{Zim}$ babwe $^{7}$ and in the Eastern Transvaal, South Africa. ${ }^{8}$ Sporadic cases have been recorded in Central African Republic ${ }^{9}$ and Botswan $a^{10}$ but there is no recent evidence of donovanosis in West Africa despite earlier reports in the literature. ${ }^{112}$

In South Africa most large towns have a designated STD clinic run by the City Health Department of the local municipal council.
The numbers of conditions diagnosed are recorded in the annual reports of the local Medical Officer of Health (MOH) but no STD data are available for those patients seen in district or missionary hospitals, polyclinics or other health centres.

Donovanosis was first recognised in South Africa in $1916^{13}$ but received little mention until the 1980s when cases were diagnosed in E. Transvaal. ${ }^{8}$ Elsewhere in the country donovanosis has been reported infrequently: only one case was diagnosed in two studies of men with GUD in Johannesburg, Transvaal in $1981^{14}$ and Durban, Natal in $1985 .{ }^{15}$ During 1988 a rapid staining technique for the detection of Donovan bodies in tissue smears was introduced at this clinic. ${ }^{16}$ Awareness of donovanosis increased and more cases were identified suggesting either previous under-reporting or the evolution of a current epidemic.

GUD and donovanosis in particular are implicated as risk factors for acquiring HIV-1 infection in local men. ${ }^{17}$ The importance of early and adequate management of GUD in reducing HIV-l transmission is recognised by WHO as a strategic tool for STD and AIDS programmes at national level. ${ }^{18}$ In the light of the increased awareness of GUD as a risk factor for HIV-l, this study investigated recent trends in donovanosis in Durban and discusses the evidence for a current epidemic.

\section{Methods}

The annual reports of the $\mathrm{MOH}$ for Durban were reviewed for references to new cases of donovanosis or granuloma inguinale against attenders at the City Health STD Clinic, King Edward VIII Hospital, every year annually from 1958. Complete records for the number of new patients with STD and GUD 1967-1988 were also available. The City Health Clinic is the only designated STD clinic serving the black community in Durban.

Prior to 1988 all reported cases of donovanosis at this clinic were diagnosed clinically. During 1988 a new rapid technique, the RapiDiff test, based on a modification of the Giemsa method, was introduced for the detection of Donovan bodies. Donovanosis was diagnosed by the characteristic appearances of multiple pink-purple bacillary bodies with an unstained capsule in mononuclear cells. The age, sex and recent place of residence of patients with confirmed donovanosis was recorded.

Tissue smears were prepared from patients with GUD lesions suggestive of donovanosis, 


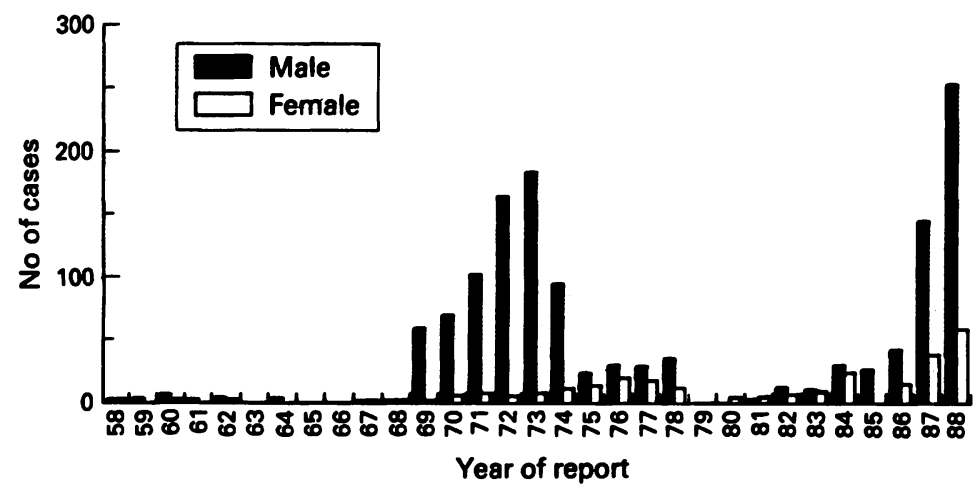

Figure 1 Numbers of Donovanosis cases recorded in the Annual Reports of the Medical Officer of Health for Durban, 1958-1988.

that is, beefy-red, non-indurated and nonsuperficial lesions with well-demarcated edges and a diameter of greater than $5 \mathrm{~mm}$. Ulcers with excess debris were initially cleaned gently with a dry swab. Smears were obtained by rolling a cotton-tipped swab firmly over the ulcer surface and depositing the material collected by rolling the swab across a glass slide. When lack of reagents or previous antibiotic treatment precluded identification of the organisms, a clinical diagnosis was made. Smears were stained and examined on direct microscopy by trained medical and laboratory staff.

\section{Results}

Donovanosis was first recorded in the annual records in 1958 (fig. 1). Cases were sporadic until 1969-1974 when a peak of 187 men with donovanosis was followed by a decline to zero in 1979. Between 1977-1986 only 280 cases were recorded. Reported cases increased significantly in 1987 and continued in 1988 when 313 (256 men, 56 women) were identified. These two peaks in the number of cases of donovanosis did not appear to be related to either increases in the total annual numbers of recorded cases of GUD or new attenders with STD (fig. 2). In both peaks the increase in cases reported in men was greater than that in women. The male to female ratio of cases in 1987 was $3 \cdot 9: 1$ and in 1988 was $4 \cdot 5: 1$.

Of the 313 cases reported in 1988, Donovan

Figure 2 Numbers of cases of genital ulcer disease and new attenders with STD recorded in the annual report of the Medical Officer of Health for Durban 1967-1988.
Table Age and sex of patients with donovanosis

\begin{tabular}{lllll}
\hline $\begin{array}{l}\text { Age } \\
\text { (year) }\end{array}$ & $\begin{array}{l}\text { Male } \\
N=130\end{array}$ & $\%$ & $\begin{array}{l}\text { Female } \\
N=41\end{array}$ & $\%$ \\
\hline $16-19$ & 29 & 22.3 & 18 & 43.9 \\
$20-29$ & 83 & 63.9 & 21 & 51.2 \\
$30-39$ & 12 & 9.2 & 1 & 2.4 \\
$40-49$ & 1 & 0.8 & 1 & 2.4 \\
$50-59$ & 4 & 3.1 & - & - \\
$60-69$ & 1 & 0.8 & - & - \\
\hline
\end{tabular}

bodies were detected in tissue smears stained by RapiDiff in 169 (129 men, 40 women) and a histological diagnosis was made in two cases. The remaining 142 (126 men, 16 women) were diagnosed on clinical grounds. The age and sex distribution of the 171 confirmed cases are shown in the table. The majority, that is $164(96 \%)$, were in the age range 16-39. Ninety-five $(56 \%)$ came from rural areas. Four rural districts, Maphumulo, Eschowe, Umbumbulo and Empangeni were often named as places of possible disease contact. Most patients had low standards of personal hygiene and poor socioeconomic status.

\section{Discussion}

Review of the annual reports showed two peaks in donovanosis infections. Firstly between 1969 and 1974, and secondly during 1988 when 313 cases were diagnosed, the highest since records commenced. This recent increase in donovanosis could reflect either improved clinical recognition by clinic staff due to the introduction of the rapid test, previous underreporting, or a real increase in cases.

Donovanosis has often gone unrecognized in areas of low endemicity. It is also possible that in certain African settings the masking effect of treatment given for other causes of GUD could have led to donovanosis being overlooked even when highly prevalent. In the syndromic approach to the management of GUD, treatment with single dose benzathine penicillin and either a seven day course of co-trimoxazole or erythromycin is usually recommended to cover syphilis and chancroid. However, in cases of donovanosis managed by this strategy, it is likely that Donovan bodies that might be detectable at presentation would not be observed in tissue smears after seven days of therapy. Courses of antibiotics for longer than seven days are usually required for complete cure and the syndromic approach may require modification for use in areas, such as Durban, where donovanosis is prevalent. ${ }^{1920}$

Facilities were not available for tissue diagnosis in all cases diagnosed in 1988 and 142 patients were diagnosed on clinical grounds alone. In these cases either a shortage of personnel, unavailability of reagents or previous treatment precluded confirmatory testing. It is possible that inclusion of cases diagnosed clinically was open to observer bias. However, donovanosis tends to have a characteristic appearance. At this clinic the clinical diagnosis of donovanosis was found to correlate very well with the detection of Donovan bodies in tissue smears (unpublished data). Further potential sources of variation in the 
numbers of cases identified and recorded are changes in the numbers attending the clinic, services for diagnosis, the case definition, clinic staffing and disease reporting over time. In Durban both the provision of STD services and procedures for reporting STD cases have hardly altered over the last 30 years. Until 1988 all GUD cases were diagnosed on clinical grounds by experienced medical staff and personnel changes were infrequent. In 1988 herpes simplex virus (HSV) was included for the first time as a separate STD diagnosis rather than as a non-STD case. However, it is unlikely that cases were misdiagnosed as donovanosis since the appearances of typical HSV lesions are unlike donovanosis and if misdiagnosed were more likely to have been reported as chancroid. It is also possible that chancroid could have been mistaken for HSV and recorded as a non-STD before 1988 . These possible sources of error would not have been expected to alter the numbers of cases of donovanosis greatly.

Donovanosis has been reported sporadically in South Africa since $1916 .^{13}$ There were reports during the 1920 s and 1930s but thereafter there was no mention in the medical literature until the 1980 s, prompting the suggestion that donovanosis disappeared completely in the interim. ${ }^{21}$ However, the annual reports in Durban document new cases in almost every year after 1958 when the present STD classification system in South Africa was introduced. It is also possible that before then cases may have been misdiagnosed since references to "granuloma venereum" and "lymphogranuloma inguinale" suggest uncertainty in differentiating between donovanosis and lymphogranuloma venereum (LGV).

There is no obvious explanation for the increase in cases of donovanosis in Durban in 1969-1974. This peak appears to have gone unnoticed at the time and no specific control measures were introduced. The second peak in 1987-1988 was associated with a preponderance of cases in men and could reflect social change, for example, the increasing numbers of male migrant workers moving into the city from rural areas.

The epidemiology of donovanosis in populations and the impact of treatment on spread are poorly understood. Patients with donovanosis are encouraged to bring their partners in for treatment but in this population regular sexual contacts rarely have concomitant donovanosis infections. ${ }^{22}$ Asymptomatic carriage of Calymmatobacterium granulomatis has not been identified and epidemiological treatment for sexual contacts is not practised routinely. Availability of drugs in South Africa has varied very little over the years and virtually all patients responded to co-trimoxazole. Tetracycline or minocycline were given in a few cases.

Similar epidemics of donovanosis are now rare since the introduction of antibiotics and the disease has virtually been eradicated in the USA and UK. There is no current evidence of epidemics elsewhere in South Africa. The largest epidemic reported in the literature was in Dutch South New Guinea between 1922-1952 when 10000 cases were recorded from a population of less than $15000 .^{1}$ This epidemic was related to a regulated system of sexual contact with multiple sexual partners and was only brought under control by compulsory annual examination of the population and provision of treatment in newly-buil peripheral health centres. Eradication of donovanosis in Goilala, Papua New Guinea was only achieved after antibiotic treatment of cases identified during house to house visits. ${ }^{2}$ Two further epidemic peaks were reported in Papua New Guinea in 1970 and 1975 but these were not explained satisfactorily. ${ }^{23}$ In India ${ }^{24}$ and Papua New Guinea ${ }^{25}$ prostitutes have been implicated as source contacts of patients with donovanosis. However, in studies of men and women with GUD in Durban no prostitutes were identified and contact with prostitutes was uncommon. ${ }^{1920}$ More recently a small outbreak involving a prostitute and her clients was reported in Houston, Texas, USA but was limited to 20 cases. $^{26}$

Many of the epidemiological features of donovanosis in Durban reported in this study were similar to those observed elsewhere. Patients tended to be of low socioeconomic status with poor standards of personal hygiene and low levels of knowledge of the infectivity of STD. Social upheaval is a well recognised factor in increasing the spread of STD and has probably contributed to the increase in donovanosis. In recent years the population of Durban and surrounding districts has increased dramatically, mainly through migration from rural areas, although exact figures are unavailable. Natal and Kwazulu have been affected by political and civil unrest and many people have had to relocate to squalid shack dwellings and squatter camps with few basic amenities on the outskirts of the city.

HIV infection is now an increasing problem in South Africa. Durban appears to be particularly affected. ${ }^{27}$ In a recent survey of the geographic distribution of cumulative AIDS cases in South Africa $49 \%$ of heterosexuals with AIDS were from the Durban, Kwazulu and Natal regions. ${ }^{28}$ AIDS cases amongst heterosexuals were more common amongs blacks $(96 \%)$ than other ethnic groups ${ }^{28}$ and the high prevalance of STD in this group especially GUD may have contributed to this. ${ }^{17}$ Donovanosis causes GUD that may be extensive and bleed readily. Lesions are not always painful and do not preclude sexual intercourse. A local study found that $44 \%$ of men and $80 \%$ of women with donovanosis had continued with sexual intercourse despite the presence of genital lesions. ${ }^{29}$ In Durban donovanosis has been implicated in HIV-1 transmission in men. ${ }^{17}$ The probability of HIV-1 infection was significantly greater in men with lesions present for three months or longer than those with ulcers for a lesser period. Control of STD and particularly GUD is now a crucia component of HIV control in Southern Africa Increased awareness and improved surveillance of donovanosis elsewhere in Africa could lead to identification of further epidemics and 
possibly lessen the spread of HIV-l infection amongst populations in whom the condition is endemic and has gone unrecognised.

The author thanks Mr K Coetzee, Department of Microbiology, University of Natal Medical School, Mr B Zulu, Durban City Health Department, for technical assistance and Dr R Keenlyside, Department of Genitourinary Medicine, Middlesex Hospital, London, for helpful comments and critical review of the manuscript.

1 Vogel LC, Richens J. Donovanosis in Dutch South New Guinea: History, evolution of the epidemic and control. Papua New Guinea Med ๆ 1989; 32:203-18.

2 Zigas V. A donovanosis project in Goilala (1951-1954) Papua New Guinea Med f 1971;14:148-9.

3 Latif AS. Granuloma inguinale. In: Osoba AO, ed. Clinical tropical medicine and communicable diseases. London: Balliere 1987; Vol 2:163-8.

4 McElligot GLM. Venereal disease in the tropics. Br $\mathcal{Y}$ Venereal Dis 1951;27:122-6.

5 Osoba AO. Sexually transmitted diseases in tropical Africa. Br $\mathcal{F}$ Venereal Dis 1981;57:89-94.

6 Bhagwandeen BS, Naik KG. Granuloma venereum (granuloma inguinale) in Zambia. E Afr Med $\mathcal{f} 1977 ; 11$ : loma inguir

7 Latif AS, Mason PR, Paraiwa E. The treatment of donovanosis (granuloma inguinale). Sex Transm Dis 1988; 15:27-9.

8 Wistrand $R$, Wegerhoff $F$. Granuloma inguinale in the Eastern Transvaal. S Afr Med $\mathcal{F}$ 1985;67:13-5.

9 Lala B, Widy-Wirski R, D'Costa JF, Kado P. Premières observations de donovanosis en Centrafrique et efficacité du traitement avec sulphamethoxazole-trimethoprime injectable. Medicine d'Afrique Noire 1982;29:1-5.

10 Veen J. Granuloma inguinale in Botswana. Trop Geogr Med 1979;31:309-10.

11 Willcox RR. Prevalence of venereal disease in British West
Africa. W Afr Med f 1956;5:103-11

12 Willcox RR. Venereal disease in British West Africa. $\mathrm{Br} \mathfrak{F}$ Venereal Dis 1946;22:63-76.

13 Ricono M. Yaws and similar diseases in South Africa. South African Medical Record 1916;14:83-9.

14 Duncan MO, Bilgeri YR, Fehler HG, Ballard RC. The diagnosis of sexually acquired genital ulcerations in black patients in Johannesburg. Southern African fournal of Sexually Transmitted Diseases 1981;1:20-3.

15 Coovadia YM, Kharsany A, Hoosen A. The microbial aetiology of genital ulcers in black men in Durban, South aetiology of genital ulcers in black men

16 O'Farrell N, Hoosen A, Coetzee K, van den Ende J. A rapid stain for the diagnosis of granuloma inguinale. Genitourin Med 1990;66:200-1.

17 O'Farrell N, Windsor I, Becker P. HIV-1 infection among heterosexual attenders at a Sexually Transmitted Diseases Clinic in Durban. S Afr Med f 1991;80:17-20.

18 WHO. Prevention of sexual transmission of human immunodeficiency virus. WHO, 1990, AIDS Series 6.

19 O'Farrell N, Hoosen AA, Coetzee KD, van den Ende J. Genital ulcer disease in women in Durban, South Africa. Genitourin Med 1991;67:322-6.

20 O'Farrell N, Hoosen AA, Coetzee KD, van den Ende J. Genital ulcer disease in men in Durban, South Africa. Genital ulcer disease in men in
Genitourin Med 1991;67;327-30.

21 Freinkel AL. The enigma of granuloma inguinale in South Africa. $S$ Afr Med $\mathcal{F}$ 1990;77:301-3.

22 O'Farrell N. Clinico-epidemiological study of donovanosis in Durban, South Africa. Genitourin Med (in press).

23 Kuberski T, Phillips P, Tabua TW. Status of granuloma inguinale in Papua New Guinea. Papua New Guinea Med f 1979;22:5-12.

24 Lal S, Nicholas C. Epidemiological and clinical features in 165 cases of granuloma inguinale. $\mathrm{Br} \mathcal{F}$ Venereal Dis 1970;46:461-3.

25 Maddocks I. Donovanosis in Papua. Papua New Guinea Med ₹ 1967;10:49-54.

26 Rosen T, Tschen JA, Ramsdell W, Moore J, Markham B. Granuloma inguinale. $f \mathrm{Am}$ Acad Dermatol 1984; 11:433-7.

27 O'Farrell N. Doomsday forecasts of the AIDS epidemicwhither Durban? S Afr Med f 1991;79:566.

28 Department of National Health and Population Development. AIDS in South Africa: Status on World AIDS Day 1991. Epidemiological Comments 1991;18:229-47.

29 O'Farrell N, Hoosen AA, Coetzee KD, van den Ende J. Sexual behaviour in Zulu men and women with genital ulcer disease. Genitourin Med 1992;68:245-8. 